\title{
Correction to "Vitamin D: An Evidence-Based Review"
}

In the abovementioned article (Kulie T, Groff A, Redmer J, Hounshell J, Schrager S.J Am Board Fam Med 2009;22(6):698-706), the AAP was referred to as the Association of American Physicians and the Association of American Pediatrics. The organization should have been entitled the American Academy of Pediatrics. The electronic version on the JABFM website has been corrected. We apologize for the error, and we regret any confusion or inconvenience it may have caused.

(doi: 10.3122/jabfm.2010.01.090256.) 